\title{
Origins of Wilson's Warblers migrating through southwest Canada: Adding value to banding data by using stable isotopes and genetic markers
}

https://doi.org/10.1515/ami-2018-0002

Received July 7, 2018; accepted September 12, 2018

\begin{abstract}
Stopovers used by birds during migration concentrate individuals from broad geographic areas potentially providing important information on catchment areas of birds moving through these sites. We combined stable isotope $\left(\delta^{2} \mathrm{H}\right)$, genetic fingerprinting and band recovery data to delineate the molt origins of Wilson's Warblers (Cardellina pusilla) migrating through a stopover site in southwestern Canada in the fall. We assessed changes in $\delta^{2} \mathrm{H}_{\mathrm{f}}$ indicating latitudinal origins with ordinal date to show this species likely underwent leapfrog migration through this site. Using the combined approach to determine origins, Wilson's Warblers migrating through southwestern Alberta in 2015 were mostly from the western boreal population $(\mathrm{n}=155,96 \%)$ with some individuals from the Pacific Northwest ( $\mathrm{n}=1,0.6 \%$ ), Rocky Mountain $(\mathrm{n}=2,1.2 \%)$ and eastern boreal $(\mathrm{n}=3,1.8 \%)$ populations. Our results suggest that individuals migrating through our study site come from a broad catchment area potentially from a large part of northwestern North America. Future studies should link population changes at banding stations with other information to determine associations with large-scale landscape-level drivers (e.g. climate, land use).
\end{abstract}

Keywords: annual cycle, deuterium, genescape, leapfrog, migratory connectivity, isoscape

\footnotetext{
*Corresponding author: Kevin J. Kardynal, Environment and Climate Change Canada, Science and Technology Branch, Saskatoon, Canada, E-mail: kevin.kardynal@canada.ca Douglas M. Collister, Calgary Bird Banding Society, Calgary, Canada Keith A. Hobson, Department of Biology, University of Western Ontario, London, Canada

Keith A. Hobson, Environment and Climate Change Canada, Science and Technology Branch, Saskatoon, Canada
}

\section{Introduction}

Determining spatial links between areas used during different parts of a species' annual cycle is crucial to their conservation [1-3]. During migration, individuals from multiple populations may concentrate at specific stopover sites particularly in areas where suitable habitat is limited, presenting an opportunity to determine broad areas of potential origin [4]. Such information gained at stopovers or 'migration monitoring stations' can potentially be useful in assessing population trajectories for large regions currently inadequately monitored [e.g. boreal forest; 5,6] and for focusing conservation measures.

Several methods have been used to estimate migratory connectivity or 'source' catchment areas for migratory birds including extrinsic (e.g. geolocators, GPS tags), intrinsic (e.g. isotope, genetics), morphometrics and band return data [reviewed in 7]. Particularly valuable towards this objective for species too small to carry external tracking devices have been developments in the use of intrinsic markers over the last decade. For example, the advent of high-resolution genetic analysis has revealed considerable spatial structure in breeding populations that can be used when assessing origins of individuals sampled during the non-breeding season [8]. This approach can correctly identify with high confidence the breeding origins of individuals when baseline population genetic structure is known [8-10]. Additionally, predictable patterns in the deuterium $\left({ }^{2} \mathrm{H}\right)$ isotope content in precipitation across continents (i.e. isoscapes) allow researchers to determine general areas of potential origin because tissue $\delta^{2} \mathrm{H}$ reflects values in the environment in which the tissue was grown [11-13]. Across North America, $\delta^{2} \mathrm{H}$ has strong latitudinal and altitudinal gradients but resolution is weaker longitudinally [11] making for ambiguity in assignments to origin in the absence of other information. By combining information from multiple sources, our ability to make inferences regarding origins of migratory birds can be made more precise [14-16]. 
Wilson's Warbler (Cardellina pusilla) breeds throughout northwestern North America, south to California and Montana and east throughout much of the boreal forest, and winters primarily in Central America. Migration patterns, morphology and genetics in this species have been relatively well studied with research indicating at least six well-segregated populations during both breeding and wintering periods $[8,16,17]$ suggesting patterns of strong migratory connectivity. Of the six genetically distinct populations, the 'Alaska to Alberta' population [hereafter, western boreal; 8] spans the largest area including most of Alaska, Yukon, Northwest Territories, British Columbia, Alberta and the western half of Saskatchewan (Figure 1). Wilson's Warblers from within the western boreal population are expected to use different migratory routes dependent on their breeding and wintering locations [16].
For example, Wilson's Warblers breeding in the boreal forest east of the Canadian Rocky Mountain and Mackenzie Mountain ranges could be expected to migrate south on the east side of these mountain chains $[8,18]$. On the other hand, birds breeding west of these mountains might migrate southward avoiding passage over mountain peaks although migration routes may vary depending on season [19]. Wilson's Warbler populations in the western part of its breeding range generally undergo a leapfrog migration pattern in the fall where individuals breeding farther north tend to initiate migration earlier than southern populations thus arriving at southern stopover sites first $[20,21]$.

Use of a single approach or marker to determine migratory connectivity can lead to low-resolution results for broad-ranging species. For example, similarities in precipitation $\delta^{2} \mathrm{H}$ values in Alaska and the Canadian

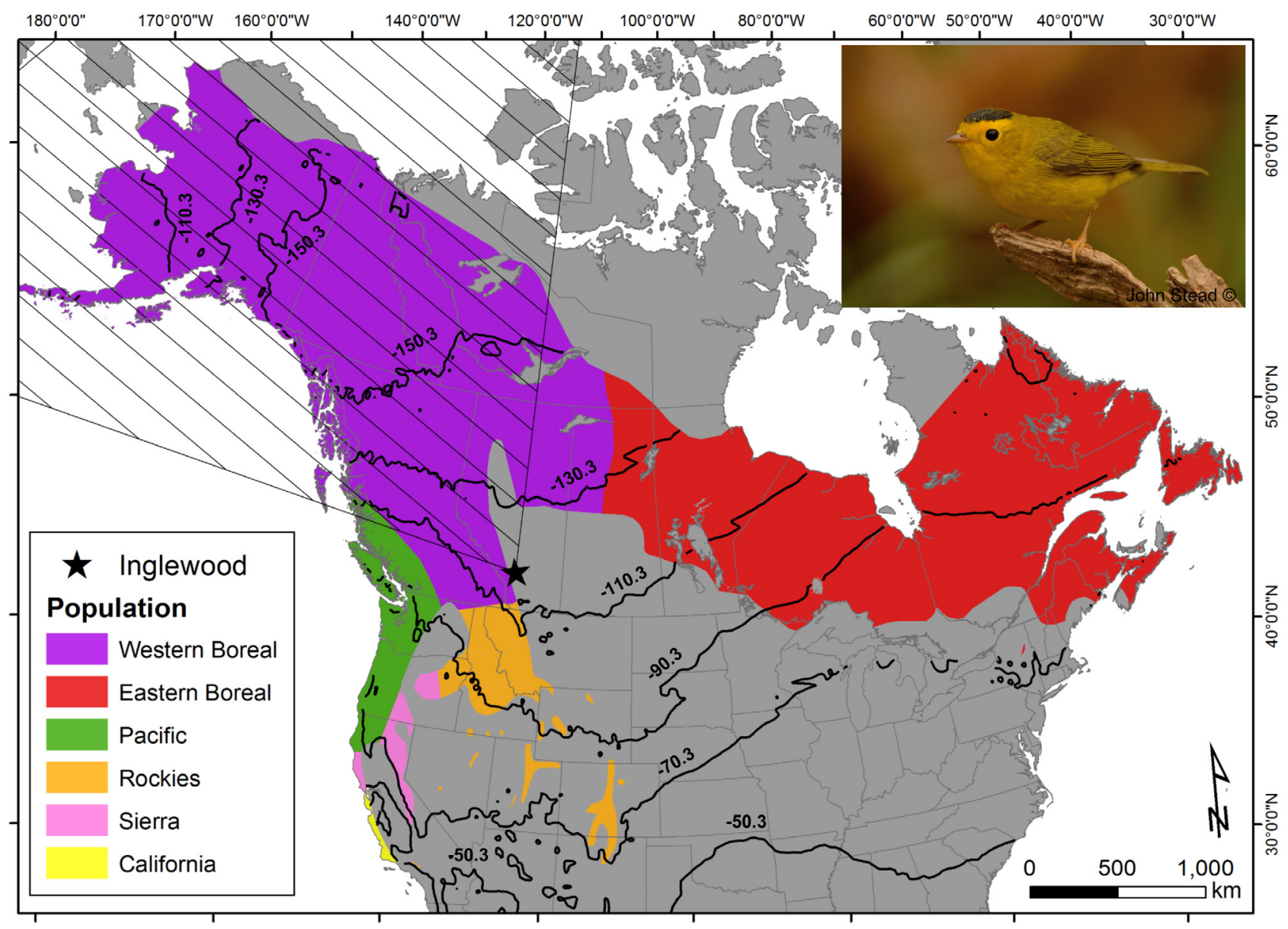

Figure 1. Location of the Inglewood Bird Sanctuary in Calgary, Alberta, Canada where Wilson's Warblers were sampled for genetic and feather hydrogen isotope analysis $\left(\delta^{2} \mathrm{H}_{\mathrm{f}}\right)$ in fall 2004, 2008 and 2015 in relation to approximate 'genetic' population boundaries on the breeding range from Ruegg, Anderson [8]. The hashed area represents the portion of the breeding range from which movement vectors represent $85 \%$ of band-recovery data from birds captured during migration from [18]. Population boundaries and movement vector data were used in the assignment to origin analyses (see Methods). Countours represent isotopic gradients in mean growing season precipitation $\delta^{2} \mathrm{H}$ [11] converted to equivelant $\delta^{2} \mathrm{H}_{\mathrm{f}}$ values for long-distance non-ground foraging birds [12]. Photo of adult male Wilson's Warbler during fall migration is inset (John Stead@). 
Rocky Mountains can lead to ambiguous determination of origins particularly for wide-ranging species [22]. Further, only large catchment areas can be identified for northern populations of Wilson's Warbler using genetic loci in [8]. Here, we combine multiple approaches to delineate the molt origins and phenology of juvenile and adult Wilson's Warblers caught during fall migration at a stopover site in Calgary, Alberta, in southwestern Canada. This site lies 45 $\mathrm{km}$ to the east of the Wilson's Warbler breeding range and has the potential to capture birds breeding from a broad geographic area across northwestern North America. A preliminary probabilistic assignment to origin using feather $\delta^{2} \mathrm{H}\left(\delta^{2} \mathrm{H}_{\mathrm{f}}\right)$ from birds captured in 2004 and 2008 at our study site showed Wilson's Warblers potentially originated from mountainous areas to the southwest of the capture site from within the range of the Rocky Mountain population [8]. A post-breeding northeastern movement to our study site would represent an unexpected migration pattern initially away from the wintering grounds for individuals from the Rocky Mountain population.

Our objectives were to: (1) assess which 'genetic populations' [8] migrated through our study site, (2) determine if birds underwent a leapfrog migration at this site, and (3) derive potential areas of origin of birds from using a probabilistic assignment of $\delta^{2} \mathrm{H}_{\mathrm{f}}$, genetics and movement vector data information. To accomplish these objectives, we assessed population structure of sampled individuals using multiple methods from birds captured in the fall of 2015. Assignment to origin analyses for the 2015 sample thus included spatial masks to delimit the potential breeding (adult) or natal (juvenile) origins of birds migrating through our study area based on population ranges of individuals determined from genetic analysis [8], movement vector data from band recoveries [14,18] and $\delta^{2} \mathrm{H}_{\mathrm{f}}$. We expected birds sampled at our study site to originate from the western boreal or Rocky Mountain populations with most individuals deriving from areas east of the Rocky Mountains. Similar to other studies [20,21], we hypothesized that birds arriving at our study site would exhibit a leapfrog pattern of migration with individuals from northern populations arriving before southern populations using $\delta^{2} \mathrm{H}_{\mathrm{f}}$ as a proxy for breeding latitude. This study acts as a template for increasing spatial resolution when assessing migratory connectivity by combining multiple types of data (e.g. $\delta^{2} \mathrm{H}_{\mathrm{f}}$, genetics and other methods; [8,23]). It also augments the considerable amount of research conducted on the migration of Wilson's Warblers in the southwestern portion of this species' range to areas outside of that region.

\section{Methods}

Birds were captured at Inglewood Bird Sanctuary in Calgary, Alberta, Canada (Figure 1) during fall migration (5 August to 30 September) in 2004, 2008 and 2015. Individuals were identified to species, were aged, sexed and fit with a uniquely numbered USGS metal band. A single outer rectrix feather was sampled from each bird and placed in a paper envelope until analyses. Birds were released immediately after sampling. Feather samples were used for stable isotope analysis and the base of the rachis of each feather including the tip was clipped and subsequently stored in an envelope for genetic analysis. The study site is within the Prairie ecozone just east of the aspen parkland ecoregion and the foothills of the Rocky Mountains. Habitat mostly consists of native shrub and forb understory beneath an open riparian balsam poplar (Populus balsamifera) forest along the Bow River in the center of Calgary, a city of approximately 1.3 million people.

\subsection{Stable Isotope Analysis}

Feathers were cleaned of surface oils in a 2:1 chloroform:methanol solvent rinse and prepared for $\delta^{2} \mathrm{H}$ analysis at the Stable Isotope Hydrology and Ecology Laboratory of Environment Canada in Saskatoon, Canada. Stable-hydrogen isotope analyses of feathers were conducted using the comparative equilibration method described by Wassenaar and Hobson (2003) through the use of three calibrated keratin hydrogen-isotope reference materials. Stable-hydrogen isotope measurements were performed on $\mathrm{H}_{2}$ derived from high-temperature $\left(1350^{\circ} \mathrm{C}\right)$ flash pyrolysis of $350 \pm 10 \mu \mathrm{g}$ feather subsamples using continuous-flow isotope-ratio mass spectrometry. All results are for nonexchangeable $\delta^{2} \mathrm{H}$ expressed in the typical delta notation, in units of per mil (\%o), and normalized on the Vienna Standard Mean Ocean Water - Standard Light Antarctic Precipitation (VSMOW-SLAP) standard scale. Measurement of three keratin laboratory reference materials (CFS, CHS, BWB; corrected for linear instrumental drift) were both accurate and precise with typical mean $\delta^{2} \mathrm{H} \pm \mathrm{SD}$ values of $-147.4 \pm 0.79 \%$ o $(\mathrm{n}=5)$, $-187 \pm 0.56 \% 0(n=5)$ and $-108 \pm 0.33 \% 0(n=5)$ per autorun, respectively. A control keratin reference yielded a 6-month $\mathrm{SD}$ of $\pm 3.3 \%$ o $(\mathrm{n}=76)$.

\subsection{Genetic Analysis}

The base of the rachis (calamus) of each feather sample collected in 2015 was used in the genetic analysis. 
Samples were analyzed at the qb3 Genomics Sequencing Laboratory at the University of California, Los Angeles. We used a high-resolution genetic marker approach that sequences data in a single nucleotide polymorphism (SNP), DNA sequence variation. This method is useful for interpreting differences in the genetic structure of a single nucleotide between individuals or homologous chromosomes [8]. SNP-specific assays that target small fragments of sequence around the SNP loci of interest and can be advantageous in cases where the DNA is highly fragmented or available only in very small quantities [24], such as in passerine feathers. Details of genetic analyses can be found in [8].

\subsection{Data Analysis}

Using only the data from 2015 we first checked for differences in $\delta^{2} \mathrm{H}_{\mathrm{f}}$ among Wilson's Warbler populations defined by genetic analysis [8] using the Kruskal-Wallis test using only hatch year birds and then for all ages. We removed the only individual from the Pacific Northwest population for this analysis due to a lack of replicates. We then used this approach to assess differences in $\delta^{2} \mathrm{H}_{\mathrm{f}}$ between sexes and ages within only the western boreal population. A model with $\delta^{2} \mathrm{H}_{\mathrm{f}}$ as the response variable and ordinal date as the independent variable was analyzed to determine if populations underwent a leapfrog migration pattern. We conducted this analysis using the entire dataset (i.e. all years, individuals) as well as only birds caught in 2015 from the western boreal population. We used Hartigan's test to determine if abundance of birds differed from unimodality with ordinal date using the 'multimode' R statistical package [25]. From this analysis, we then assessed differences in $\delta^{2} \mathrm{H}_{\mathrm{f}}$ between these groups using the Kruskal-Wallis test to determine if earlier arriving birds had lower isotope values than later arriving birds indicating origins from more northern latitudes (i.e. leapfrog migration). Results of all tests were considered significant at $p<0.05$.

\subsection{Assignment to Origin}

To delineate probable origins of Wilson's Warblers, we applied a spatially-explicit likelihood assignment method [26,27] using $\delta^{2} \mathrm{H}_{\mathrm{f}}$ for each sample, separately. To accomplish this, we converted an amount-weighted growing season precipitation surface from [11] to a feather isoscape using the calibration equation for long-distance non-ground foraging birds $\delta^{2} \mathrm{H}_{\mathrm{f}}=-17.57+0.95^{\star} \delta^{2} \mathrm{H}_{\mathrm{p}}$ from [12]. We incorporated the standard deviation of the residuals of the linear regression model $(\mathrm{SD}=14.4 \%$ ) from the calibration as error into the assignments. We edited the digital breeding range of Wilson's Warbler [28] to reflect the geographic boundaries of genetically distinct breeding populations from [8; Figure 1]. Based on the results of the genetic analysis, we then split the isotope data from 2015 by breeding population to determine breeding or natal origins of individuals to the range of their population and separately to the western boreal portion of the species' breeding range. We further delimited all assignments to the western boreal population's breeding range using the movement vectors representing the upper $85 \%$ of the probability distribution for bird recaptures from the IBS banding station [18; Figure 1]. For a final assignment to origin depiction, we used all birds from 2004 and 2008 and only those from the western boreal population captured in 2015. We also assigned early and later individuals from the Kruskal-Wallis test in separate analyses to depict potential origins for those groups. We then scaled ( 0 to 1 ) the resulting rasters for early and late arriving birds and calculated the difference between each raster cell for a depiction of spatial overlap in probable origins.

We used a conservative odds ratio of 2:1 to assign individuals to potential natal origin where cells in the isoscape in the upper $67 \%$ of probabilities were considered as likely (1) origins and all others were considered unlikely [0;27]. Assignments conducted for feather samples resulted in a spatially explicit binary surface for each individual, which were then summed across assignments for all other individuals to represent potential origins for the entire sample and then for each 'population' based on their determined genetic population in separate analyses. We also ran the analyses using the breeding range of the assigned population including the western boreal population for Wilson's Warbler to depict potential origins. Manipulation of digital files, assignment to origin and other analyses were conducted using multiple packages including 'raster' 2.6-7 [29], maptools 0.8-39 [30] and 'permute' 0.9-4 [31] $\mathrm{n}$ the R statistical computing environment 3.3.3 [32] and ArcMap 10.1 [ESRI 33].

\section{Results}

\subsection{Genetic Analysis}

The high-resolution genetic analysis indicated that the majority (96.3\%) of birds migrating through our study site in 2015 were derived from the western boreal population group $(n=155)$. The genetic assessment for birds that were assigned to this group had a median probability of 
100\% (range: 96 - 100\%). The remaining birds were from the eastern boreal $(n=3)$, Pacific Northwest $(n=1)$ or the Rocky Mountain $(\mathrm{n}=2)$ populations. The genetic analysis indicated that the eastern boreal population had a $100 \%$ probability for individuals assigned to this population. The individual from the Pacific Northwest population had a probability of $51 \%$ assignment accuracy with the next highest probability being for the western boreal population (49\%). The two individuals from the Rocky Mountain population had probabilities of belonging to this group of $89 \%$ and $58 \%$ with probabilities of $11 \%$ and $42 \%$, respectively, of being from the western boreal population. All Wilson's Warblers determined not from the western boreal population were juveniles.

\subsection{Temporal $\delta^{2} \mathrm{H}$ Patterns}

Using the complete dataset from 2015, the Kruskal-Wallis test assessing differences in $\delta^{2} \mathrm{H}_{\mathrm{f}}$ between populations was significant both when only hatch year birds were included $\left(\chi^{2}=17.79, \mathrm{df}=3, p<0.0005\right)$ and when all ages were combined ( $\chi^{2}=22.86, \mathrm{df}=3, p<0.001$; Figure 2). Individuals from the eastern boreal $(\overline{\mathrm{x}}=-148.75 \pm 18.53$ $\%, \mathrm{n}=3)$ and Rocky Mountain ( $\overline{\mathrm{x}}=-147.48 \pm 4.35 \%$, $\mathrm{n}$ = 2) populations had lower $\delta^{2} \mathrm{H}_{\mathrm{f}}$ than the western boreal population $(\overline{\mathrm{x}}=-126.84 \pm 17.35 \%)$ although samples sizes for the former populations were low (Figure 2). We found no differences in $\delta^{2} \mathrm{H}_{\mathrm{f}}$ between adult and juvenile birds $\left(\chi^{2}=0.29, \mathrm{df}=1, p=0.59\right)$, between male and female adult $\left(\chi^{2}=2.35, \mathrm{df}=2, p=0.31\right)$ or juvenile $\left(\chi^{2}=\right.$ $2.44, \mathrm{df}=2, p=0.30$ ) Wilson's Warblers from the western boreal population. Using the entire dataset (i.e. all years, populations, sexes and ages), the linear model indicated that Wilson's Warblers $\delta^{2} \mathrm{H}_{\mathrm{f}}$ increased with ordinal date ( $p$ $<0.001, r^{2}=0.23, \beta=0.94 \pm 0.08 \mathrm{SE}$; Figure 3A) suggesting a leapfrog migration pattern at our study site. This pattern was also evident when only individuals captured in 2015 from the western boreal population were analyzed $(p<$ $0.001, r^{2}=0.18, \beta=0.69 \pm 0.12 \mathrm{SE}$ ). However, substantial variability in $\delta^{2} \mathrm{H}_{\mathrm{f}}$ with ordinal date indicates mixing of populations at the stopover from approximately day 15 (18 August) of sampling through to approximately day 42 (13 September). The two individuals identified as being from the Rocky Mountain population were captured within the first 12 days of sampling and the three individuals from the eastern boreal population were captured from ordinal day 12 to 34 (Figure $3 \mathrm{~A}$ ).

The test for modality in fall capture rates with ordinal date for birds from the western boreal population in 2015 indicated that the data were not unimodal (Dip statistic: $0.05, p=0.01$ ). A visual assessment of the kernel density of captures indicated that there were two modes in the data occurring at 20 August and 8 September (antimode $=26$ August; Figure 3B). The Kruskal-Wallis analysis testing for differences in $\delta^{2} \mathrm{H}_{\mathrm{f}}$ between individuals arriving earlier to our study site versus later arriving birds from the western boreal population in 2015 was significant $\left(\chi^{2}=16.70, p\right.$ $<0.001)$. Similar to the linear model, birds that arrived earlier (before 27 August) had lower $\delta^{2} \mathrm{H}_{\mathrm{f}}$ values $(\overline{\mathrm{x}}=-138.0$ $\pm 17.7 \%$ o, $\mathrm{n}=35)$ than those that arrived later $(-123.6 \pm 15.9$ $\%, \mathrm{n}=120$ ) indicating a leapfrog migration pattern where northern breeding birds arrived first to our study site.

\subsection{Assignment to Origin}

The probabilistic assignments to natal or breeding origin analyses indicated considerable spatial and temporal structure for Wilson's Warblers migrating through our study site in southwestern Canada. Feather $\delta^{2} \mathrm{H}$ of Wilson's Warblers from the western boreal population in 2015 was highly variable as reflected in the probabilistic assignments to origin which indicated that birds could potentially derive from across much of this population's range (Figure 4A). However, the highest number of individuals from the western boreal population likely originated from an area stretching from the Rocky Mountains west of our study site through central British Columbia west to the Queen Charlotte Islands and from central Alaska in a zone from the northwest to the south

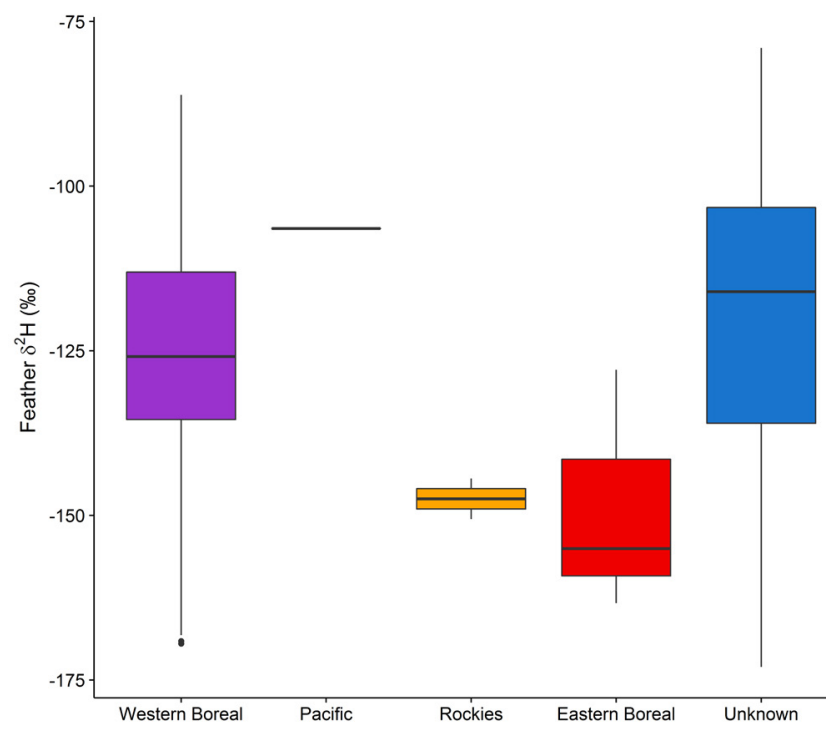

Figure 2. Box and whisker plots showing variation in feather hydrogen isotopes $\left(\delta^{2} \mathrm{H}_{\mathrm{f}}\right)$ between populations of Wilsons's Warblers sampled at the Inglewood Bird Sanctuary in Calgary, Alberta, Canada, during fall migration (August, September), 2015 and from unknown populations sampled in fall 2004 and 2008. 

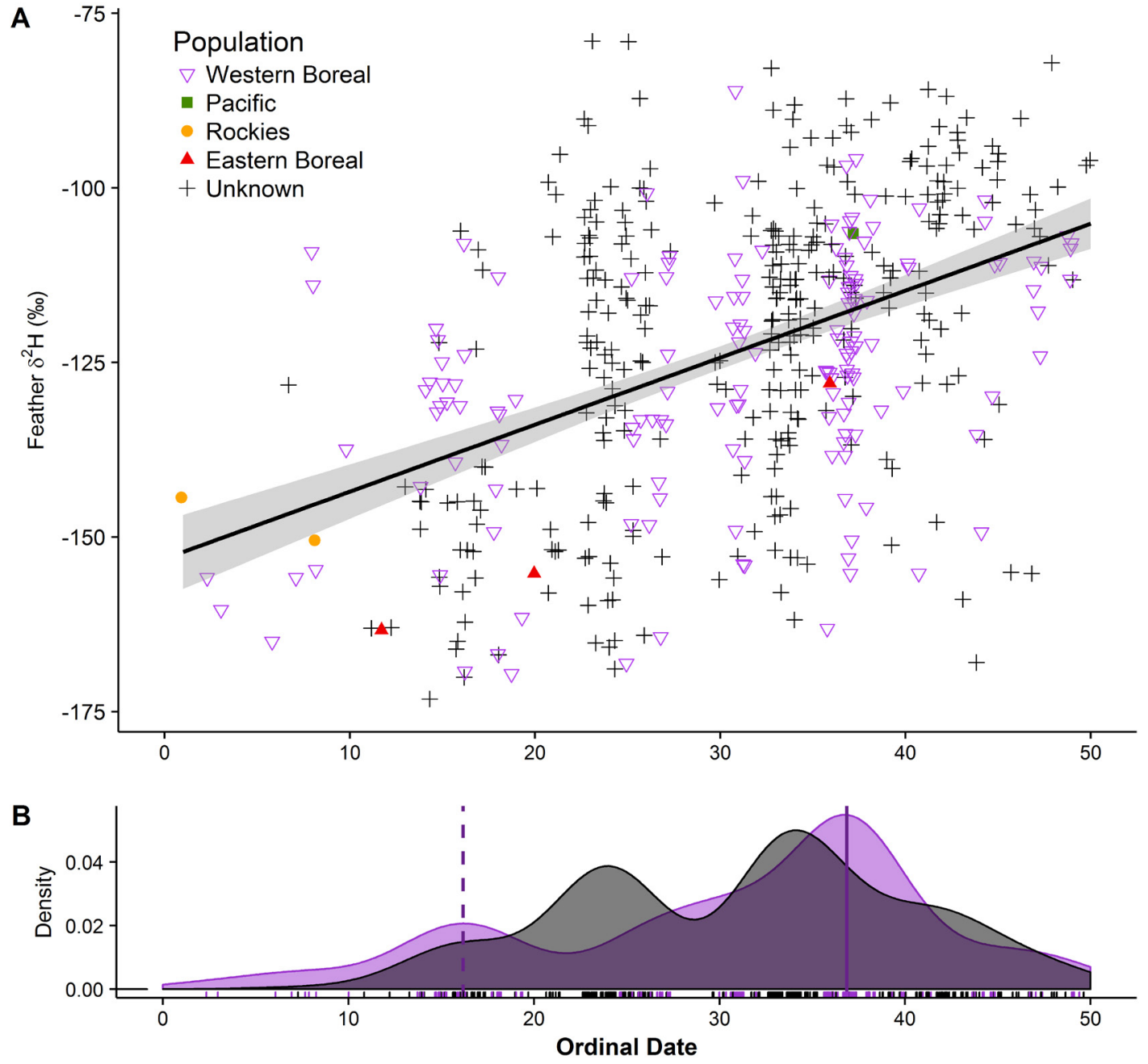

Figure 3. Relationship between ordinal date (August $4=0$ ) and feather hydrogen isotope $\left(\delta^{2} \mathrm{H}_{\mathrm{f}}\right)$ values $(\%)$ for different genetic populations of Wilson's Warblers captured during fall migration at the Inglewood Bird Sanctuary in Calgary, Alberta, August through October 2004,2008 and 2015 (A). The line represents the best fit linear model for the dataset. Genetic analysis was conducted only for birds caught in 2015 therefore captures from 2004 and 2008 are labelled as 'unknown'. Points are offset ('jittered') for clarity. Density plot showing bimodal abundance with capture date of Wilson's Warblers from the western boreal population captured in 2015 (purple; B) vs. 2004 and 2008 (grey). Modes (vertical lines) were determined from a test of multimodality (see Methods).

central part of that state. A high number of individuals also potentially originated from the southern boreal forest in Alberta through to western British Columbia or from central Alaska, with moderate numbers having origins from across much of the northern boreal forest in northern Alberta, British Columbia, Northwest Territories, Yukon and parts of Alaska. The assignments of Wilson's Warblers caught at our study site in 2004 and 2008 indicated that most birds likely originated from similar areas as in 2015 with those captured in the two earlier years possibly coming from areas slightly farther south in Canada or farther west in Alaska (Figure 4B).

When the assignment of the individual from the Pacific Northwest population was restricted to its purported range, it could have possibly derived from southwestern British Columbia and north-central Washington State (Figure 4C). Based on the probabilistic assignment that included the Pacific Northwest and western boreal breeding range, this individual possibly originated from an area southwest of our study site in south-central British Columbia or possibly from western Alaska (Figure 4D). Assignments of two individuals to the Rocky Mountain population range indicated origins from areas south of our study site in western Montana (Figure 4E). However, assignments using the Rocky Mountain and western boreal portion of the species' range indicated probable areas of provenance from far northern British Columbia and Alberta to eastern and northern Northwest Territories and eastern Alaska (Figure 4F). The assignment of the three birds from the eastern boreal population 

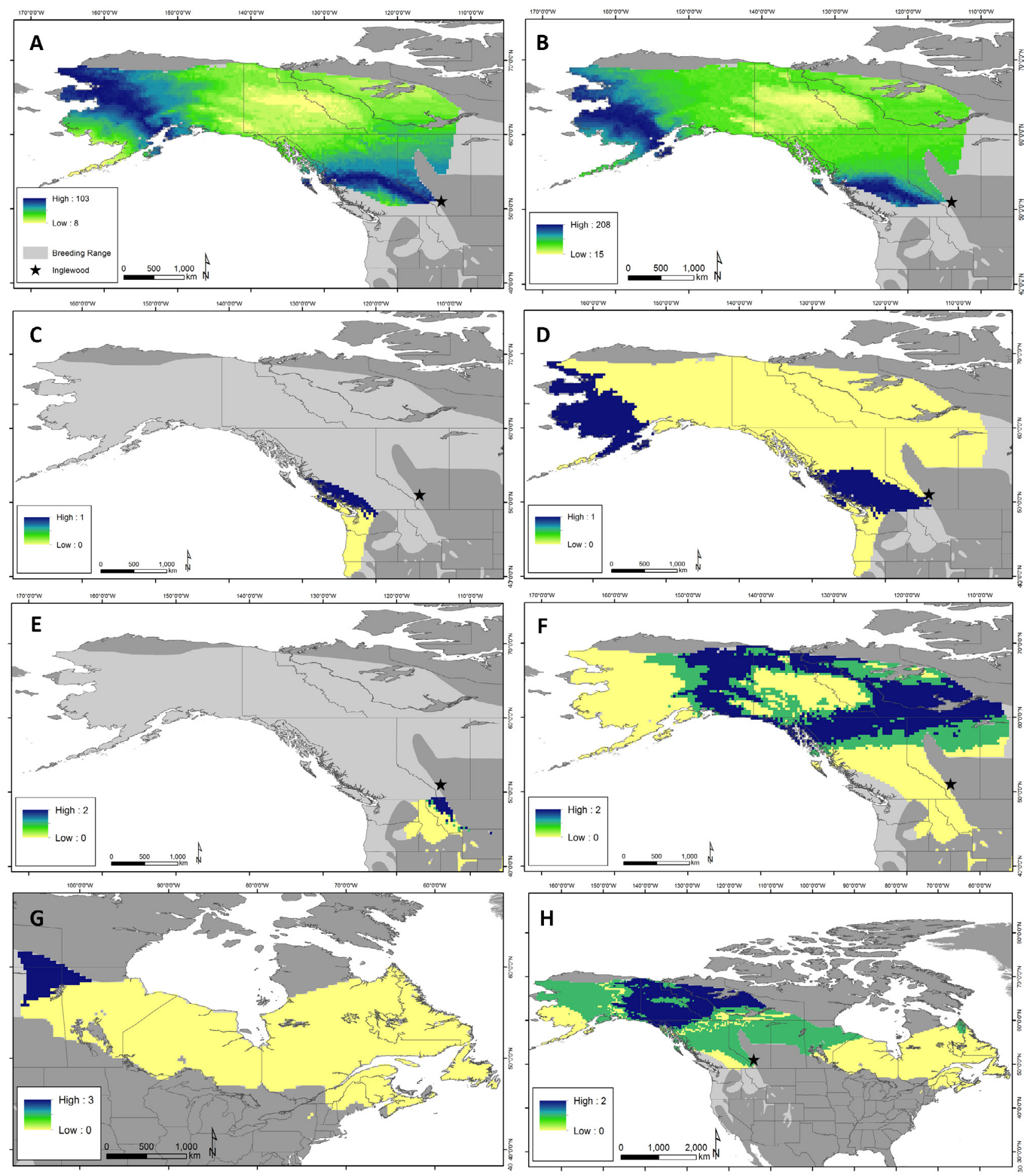

Figure 4. Probabilistic assignment to natal (hatch year) or breeding (adult) origins of Wilson's Warblers arriving to our study site at the Inglewood Bird Sanctuary in Calgary, Alberta, Canada during fall migration using feather $\delta 2 \mathrm{H}$. Population of individuals captured in 2015 were assessed using genetics to determine which population they were most likely derived [see 8]. Individuals from the western boreal population from (A) 2015 ( $n=155)$ and (B) individuals sampled in $2004(n=198 ;$ no genetic analysis), 2008 ( $n=147$; no genetic analysis) and 2015 assigned to the western boreal population range. Birds assigned to the range of their respective population (left hand figure) and then to include the range of the western boreal population (right hand figure) for individuals from the Pacific Northwest $(C, D ; n=1)$, Rocky Mountain $(E, F ; n=2)$ and eastern boreal ( $G, F ; n=3)$ populations [see 8]. Legend values indicated the potential number of individuals originating from a single cell $(\sim 17.3 \mathrm{~km} \times 17.3 \mathrm{~km})$ in the raster. 
indicated origins from within their respective range likely from areas closest to our study site in far northeastern Saskatchewan or northwest Manitoba (Figure 4G). When the assignments were allowed to have birds originating also from the western boreal range, the areas with the highest probability of origin were in the northern boreal forest in Northwest Territories and Yukon (Figure 4H).

Assignments of early vs. late arriving individuals from the western boreal population exhibited substantial differences in origins of those birds. These depictions suggested that the areas with the highest probability of origin for birds from the western boreal population arriving earlier were west and north of our study area in the foothills and mountains of Alberta and British Columbia and across much of the southern boreal forest throughout much of Alberta (Figure 5A). Central Alaska was also determined to be an area of potentially high probability of origin with much of the range within the western boreal population range having moderate probability. Later arriving individuals appeared to derive mostly from an area extending north and west from our study site from southern Alberta to central and southern British Columbia (Figure 5B). Visual examination of differences between scaled (0 to 1 ) assignment rasters of early vs. late arriving birds indicated large areas without spatial overlap in potential origins (blue and brown in Figure 5C) and smaller areas with overlap in origins (yellow in Figure 5C). Areas with high overlapping origins were west of the study site through the Rocky Mountains and scattered areas west through central British Columbia, through central Alaska and in parts of eastern Alaska, northern British Columbia and southern Yukon and Northwest Territories.

\section{Discussion}

Our combined genetic, isotopic and band recovery vector analysis of Wilson's Warblers migrating through a site in southwestern Canada during fall indicated that the majority of individuals originated from the western boreal population with a few individuals potentially deriving from the Pacific Northwest, Rocky Mountain and eastern boreal populations. The location of our study site is generally south of the western boreal population's range and therefore should preclude individuals from most other populations during migration, a result that is not surprising. The genetic analysis revealed that the three birds from the eastern boreal had 100\% probabilities of being from that population indicating that some individuals may use a western migration route to reach their wintering grounds. However, geographic delineation of western vs. eastern boreal populations using genetics is ambiguous (see [8]) and further study on the genetic variability at that intergrade will be useful. The individuals determined to be from the Pacific Northwest and Rocky Mountain populations had considerably lower genetic assignment probabilities suggesting they may be from 'hybrid zones' where individuals from different populations interbreed. Further, all birds not from the western boreal population were juveniles which were undertaking their first migration and thus their movements may not be as direct as adult birds; however, samples sizes from those populations and of juveniles vastly outweigh adults and conclusions about this pattern are speculative. Finally, the spatial population boundaries from [8] based on genetics may not be discrete and may be closer to our study site than indicated.

Feather $\delta^{2} \mathrm{H}$ of Wilson's Warblers from the western boreal population in 2015 and individuals from unknown populations in 2004 and 2008 were highly variable as reflected in the probabilistic assignments to origin which indicated that birds could potentially derive from across much of the western boreal range. The few birds purportedly from other populations based on the genetic analysis had isotopic values within the range of those for the western boreal population. Indeed, when assignments using $\delta^{2} \mathrm{H}_{\mathrm{f}}$ included the breeding range of the western boreal population, those individuals were more likely to originate from that area rather than the range of their 'genetic' population. This analysis suggests that our study site may be well-situated to capture individuals from a broad breeding catchment area that could potentially be used to monitor factors influencing populations originating particularly from the western boreal $[8,18]$. Our study site is situated near the boundary between fescue grassland (dominated by agriculture) to the east and aspen parkland and Rocky Mountain foothills to the west and may provide ample habitat for Wilson's Warblers migrating from across a broad geographic area to their wintering grounds. Such a route along the foothills of the Rocky Mountains would allow birds to avoid areas of potentially unsuitable habitat (i.e. few stopovers) in the Great Plains or mountains that may have fewer resources and more unstable weather. However, other long-distance migratory bird species migrate via the Great Plains and the Rocky Mountains [34] and this topic requires additional research.

Our assessment of changes in $\delta^{2} \mathrm{H}_{\mathrm{f}}$ with ordinal date suggests that individuals migrating through our study site undergo a leapfrog pattern of migration whereby individuals from farther north arrive at stopovers before birds from more southern breeding areas. This result 

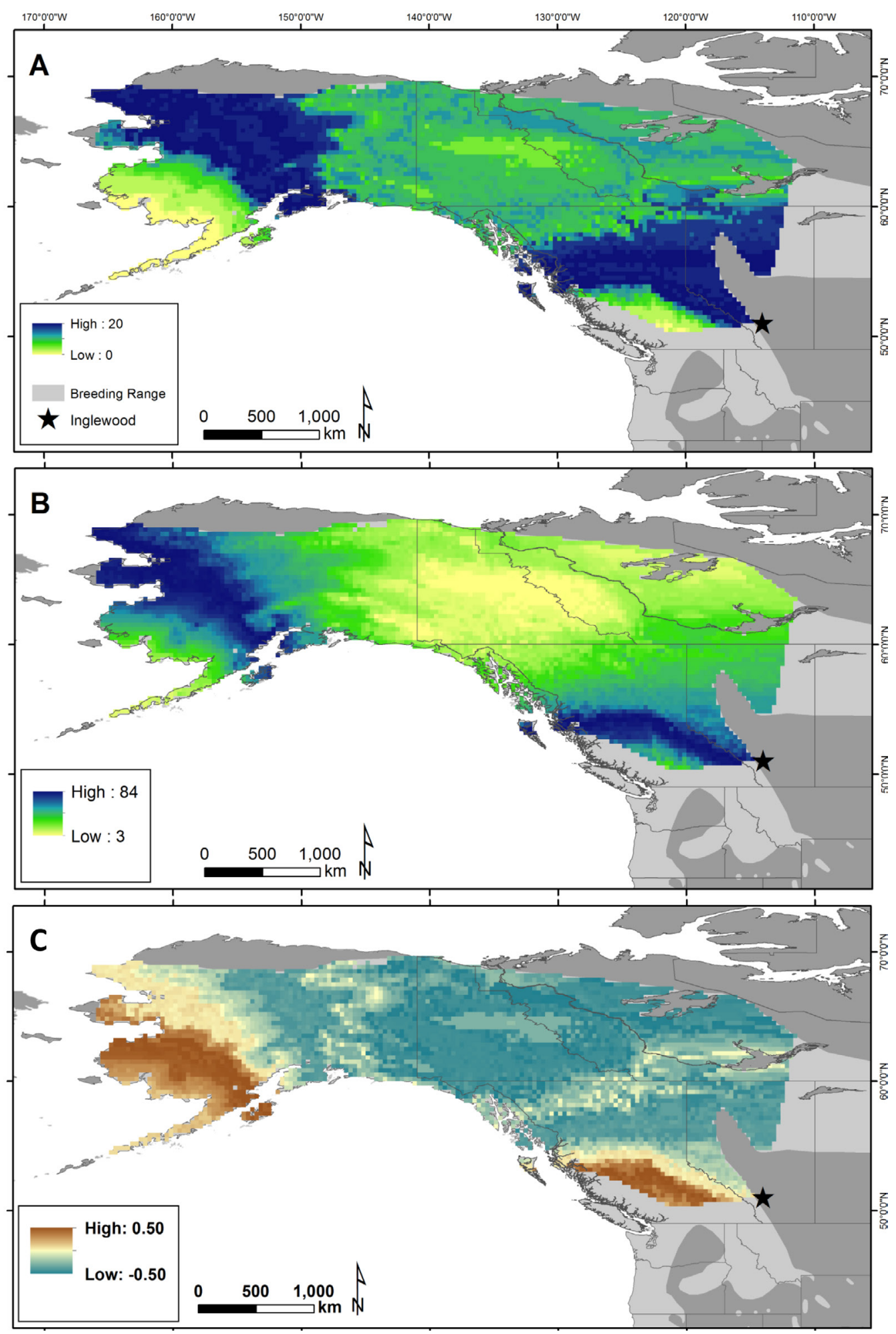

Figure 5. Assignment to probable natal (hatch year) or breeding (adult) origins of Wilson's Warblers from the western boreal population arriving early ( $A$; before 27 August, $n=35$ ) and later ( $B$; after 27 August, $n=120$ ) to our study site at the Inglewood Bird Sanctuary in Calgary, Alberta, Canada during fall migration, 2015 using feather $\delta^{2} \mathrm{H}$. Assignments were restricted to the Wilson's Warbler breeding range of the western boreal population [see 8] and to areas within $85 \%$ of the probability distribution from movement vector data [see 18]. Legend values for $A$ and $B$ indicate the potential number of individuals originating from a single cell $(\sim 17.3 \mathrm{~km} \times 17.3 \mathrm{~km})$ in the raster. The difference between rasters $(A, B)$ scaled from 0 to 1 is shown in $C$. Values $\approx 0$ (yellow) indicate little or no difference in the proportion of individuals deriving from those cells, values $\approx-0.5$ (blue) indicate a higher proportion of early arriving individuals deriving from those areas and values $\approx 0.5$ (brown) indicate higher proportions of later arriving birds. 
agrees with studies from other parts of this species' range that showed a similar behavior [20,21]. This pattern was consistent across years; however, peaks in abundance were slightly different between 2004 and 2008 compared to 2015 suggesting that migratory phenology may vary in this species. Depictions of early vs. late arriving Wilson's Warblers from the western boreal population in 2015 using $\delta^{2} \mathrm{H}_{\mathrm{f}}$ also indicate that areas farther north are likely origins for earlier arriving individuals if Alaskan parts of the range are excluded. The depiction of differences in origins of early vs. late arriving birds further supported the result that those groups derived from different areas with some overlap in the southern and far western part of its range. The assignment to origins of Wilson's Warblers caught at our study site in 2015 indicates that high numbers of birds were likely from similar areas as those captured in 2004 and 2008. Our assignment to origins suggests that Alaska is a potential part of the catchment area for our study site during fall migration, which is likely a consequence of similarities in the pattern of the underlying precipitation isoscape. However, we expect that birds from the extreme northwestern part of their range may use a migration route west of the Rocky Mountains through British Columbia and California en route to their wintering grounds.

We provide an example of combining multiple approaches to determining connectivity and catchment areas for bird species too small to carry tracking devices (e.g. geolocators). Although the genetic analysis was useful for distinguishing individuals among some populations migrating through our study site, those groupings alone provide limited information beyond large geographic regions of origin particularly for the western and eastern boreal populations. Additional research to define the geographic delineation between western and eastern boreal breeding populations or areas of intergrade would be useful in studies on migratory connectivity of Wilson's Warblers $[8,16]$. Using stable isotopes in addition to genetics allowed us to provide further refinement of potential catchment areas within the ranges of Wilson's Warbler populations [8]. For species with ranges that span broad longitudinal gradients, combining several methods can help increase precision of likely areas of origin. However, an approach similar to ours requires a relatively detailed understanding of baseline genetic structure across a species' range to which birds can be assigned. In our case, genetic evaluation allowed us to rule out potential origins south of our study site that may have also been at higher altitude (Hobson et al. 2015).

Banding and morphometric (e.g. wing length) measurements, other isotope measurements (e.g. $d^{13} \mathrm{C}$ ) and trace elements are also potentially useful for inclusion in probabilistic assignments or in restricting potential regions of origin. However, use of such data requires sufficient recapture data of banded birds to understand movement vectors or having baseline data on spatial structure of morphometrics or other elements [14,35-37]. Pre-molt movements of Wilson's Warblers may skew results for some individuals particularly where there is the possibility of birds undertaking a latitudinal migration. For example, precipitation $\delta^{2} \mathrm{H}$ gradients may vary drastically over short distances which could influence $\delta^{2} \mathrm{H}_{\mathrm{f}}$ values if these movements are associated with molt [38].

The relatively recent emphasis that the regulation of migratory wildlife populations can be influenced by factors occurring during various parts of the annual cycle has shifted the focus of research to include the non-breeding season [39,40]. For many North American avian migrants, the distribution of their breeding ranges across vast areas of the continent necessitates the use of innovative tools to elucidate spatial linkages of populations between the breeding and non-breeding seasons. Knowledge of catchment areas of these species caught at individual stopover sites can be used to link broad-scale causes of population change (e.g. climate, landscape change) for specific portions of their breeding or wintering grounds, particularly in regions with relatively little data otherwise (e.g. boreal forest). For instance, work using intrinsic markers has identified disjunct wintering grounds associated with populations of some bird species with differing population trajectories [41,42] potentially increasing our understanding of factors contributing to population trends and priorities for future research and conservation. Combining multiple methods to investigate connectivity of migratory populations will be an important tool in advancing our understanding of population regulation. However, few studies have examined causal factors that may vary in type and magnitude which may influence population trajectories across different catchment areas. A movement toward this type of research with the application of methods such as ours will be important for the conservation of migrant bird populations.

Acknowledgements: We thank the Banders-in-Charge (Steve Lane, Cyndi Smith, Shonna McLeod, Bill Taylor and Pat Mitchell) and volunteer banding assistants of the Calgary Bird Banding Society for capturing and sampling birds. This study was funded by the Calgary Bird Banding Society and through an operating grant by Environment and Climate Change Canada to KAH. Feather samples were collected under Environment Canada Bird Banding Permit 10523 and Alberta Environment and Parks Research 
Permit 56041 and Collection License 56043. C. Gryba and G. Koehler from Environment and Climate Change Canada prepared and analyzed feather samples.

\section{References}

[1] Webster MS, Marra PP. The importance of understanding migratory connectivity and cross-seasonal interactions. In: Greenberg R, Marra PP, eds. Birds of Two Worlds: the ecology and evolution of migration. Baltimore, Maryland: Johns Hopkins University Press; 2005:199-209

[2] Faaborg J, Holmes RT, Anders AD, et al. Conserving migratory land birds in the New World: Do we know enough? Ecol Appl 2010;20:398-418.

[3] Hostetler JA, Sillett TS, Marra PP. Full-annual-cycle population models for migratory birds. The Auk 2015;132:433-49.

[4] Hobson KA. Stable isotopes and the determination of avian migratory connectivity and seasonal interactions. Auk 2005;122:1037-48.

[5] Dunn EH, Altman BL, Bart J, et al. High priority needs for range-wide monitoring of North American landbirds2005.

[6] Blancher PJ. The importance of Canada's boreal forest to landbirds. - Bird Studies Canada.2003.

[7] Hobson KA, Norris DR, Kardynal KJ, Yohannes E. Animal migration: A context for using new techniques and approaches. In: Hobson KA, Wassenaar LI, eds. Tracking Animal Migration Using Stable Isotopes. London: Academic Press; 2018:1-23.

[8] Ruegg KC, Anderson EC, Paxton KL, et al. Mapping migration in a songbird using high-resolution genetic markers. Mol Ecol 2014;23:5726-39.

[9] Battey C), Linck EB, Epperly KL, et al. A migratory divide in the Painted Bunting (Passerina ciris). The American Naturalist 2018;191:259-68.

[10] Doyle JM, Katzner TE, Roemer GW, et al. Genetic structure and viability selection in the golden eagle (Aquila chrysaetos), a vagile raptor with a Holarctic distribution. Conserv Genet 2016;17:1307-22.

[11] Bowen GJ, Wassenaar LI, Hobson KA. Global application of stable hydrogen and oxygen isotopes to wildlife forensics. Oecologia 2005;143:337-48.

[12] Hobson KA, Van Wilgenburg SL, Wassenaar LI, Larson K. Linking hydrogen $\left(\delta^{2} \mathrm{H}\right)$ isotopes in feathers and precipitation: sources of variance and consequences for assignment to isoscapes. PLoS ONE 2012;7:e35137.

[13] Hobson KA. Incredible journeys. Science 2002;295:981-2.

[14] Van Wilgenburg SL, Hobson KA. Combining stable-isotope ( $\delta \mathrm{D})$ and band recovery data to improve probabilistic assignment of migratory birds to origin. Ecol Appl 2011;21:1340-51.

[15] Hobson KA, Kardynal KJ. An isotope $\left(\delta^{34} S\right)$ filter and geolocator results constrain a dual feather isoscape $\left(\delta^{2} \mathrm{H}, \delta^{13} \mathrm{C}\right)$ to identify the wintering grounds of North American Barn Swallows. The Auk: Ornithological Advances 2016;133:86-98.

[16] Rundel CW, Wunder MB, Alvarado AH, et al. Novel statistical methods for integrating genetic and stable isotope data to infer individual-level migratory connectivity. Mol Ecol 2013;22:4163-76.

[17] Irwin DE, Irwin JH, Smith TB. Genetic variation and seasonal migratory connectivity in Wilson's warblers (Wilsonia pusilla): species-level differences in nuclear DNA between western and eastern populations. Mol Ecol 2011;20:3102-15.

[18] Hobson KA, Van Wilgenburg SL, Dunn EH, Hussell DJT, Taylor PD, Collister DM. Predicting origins of passerines migrating through Canadian migration monitoring stations using stablehydrogen isotope analyses of feathers: a new tool for bird conservation. Avian Conservation and Ecology 2015;10.

[19] Ammon EM, Gilbert WM. Wilson's Warbler (Cardellina pusilla), v 2.0. In: Poole AF, Gill FB, eds. Birds of North America. Ithaca, New York, NY, USA: Cornell Lab of Ornithology; 1999.

[20] Kelly J, Atudorei V, Sharp Z, Finch D. Insights into Wilson's Warbler migration from analyses of hydrogen stable-isotope ratios. Oecologia 2002;130:216-21.

[21] Paxton KL, Van Riper C, Theimer TC, Paxton EH. Spatial and temporal migration patterns of Wilson's Warbler (Wilsonia pusilla) in the southwest as revealed by stable isotopes. Auk 2007;124:162-75.

[22] Hobson KA, Norris DR. Animal migration: A context for using new techniques and approaches. In: Hobson KA, Wassenaar LI, eds. Tracking Animal Migration Using Stable Isotopes. London: Academic Press; 2018:1-27.

[23] Kelly JF, Ruegg KC, Smit TB. Combining isotopic and genetic markers to identify breeding origins of migrant birds. Ecol Appl 2005;15:1487-94.

[24] Kraus RH, vonHoldt B, Cocchiararo B, et al. A single nucleotide polymorphism-based approach for rapid and cost-effective genetic wolf monitoring in Europe based on noninvasively collected samples. Molecular ecology resources 2015;15:295-305.

[25] Ameijeiras-Alonso J, Crujeiras RM, Rodriguez-Casal A. multimode: An R package for mode assessment. arXiv preprint arXiv: 1803.00472. 2018.

[26] Royle JA, Rubenstein DR. The role of species abundance in determining breeding origins of migratory birds with stable isotopes. Ecol Appl 2004;14:1780-8.

[27] Hobson KA, Wunder MB, Van Wilgenburg SL, Clark RG, Wassenaar LI. A method for investigating population declines of migratory birds using stable isotopes: origins of harvested lesser scaup in North America. PLoS ONE 2009;4:e7915. doi:10.1371/journal.pone.0007915.

[28] BirdLife International, NatureServe. Bird species distribution maps of the world. 1.0 ed. Cambridge, UK and NatureServe, Arlington, USA: BirdLife International; 2011.

[29] Hijmans RJ. raster: Geographic data analysis and modeling. 2.6-7. http://CRAN.R-project.org/package=raster ed2017.

[30] Bivand RS, Lewin-Koh N. maptools: Tools for Reading and Handling Spatial Objects. 0.9-2. http://CRAN.R-project.org/ package $=$ maptools ed 2017 .

[31] Simpson GL. permute: Functions for generating restricted permutations of data. 0.9-4. http://CRAN.R-project.org/ package $=$ permute ed 2016 .

[32] R Core Team. R: A language and environment for statistical computing. 3.5.0 ed. Vienna, Austria: The R Foundation for Statistical Computing. ISBN 3-900051-07-0; 2018.

[33] ESRI (Environmental Systems Resource Institute). ArcMap. 10.1 ed. Redlands, California: ESRI; 2012.

[34] Kardynal KJ, Hobson KA. The pull of the Central Flyway? Veeries breeding in western Canada migrate using an ancestral eastern route. J Field Ornithol 2017;88:262-73. 
[35] Delingat J, Hobson KA, Dierschke V, Schmaljohann H, Bairlein F. Morphometrics and stable isotopes differentiate populations of Northern Wheatears (Oenanthe oenanthe). J Ornithol 2010;152:383-95.

[36] Maggini I, Metzger B, Voss M, Voigt CC, Bairlein F. Morphometrics and stable isotopes differentiate wintering populations of a migratory bird. Movement Ecology 2016;4:20.

[37] Braune BM, Hobson KA, Malone BJ. Regional differences in collagen stable isotope and tissue trace element profiles in populations of long-tailed duck breeding in the Canadian Arctic. Sci Total Environ 2005;346:156-68.

[38] Wiegardt AK, Barton DC, Wolfe JD. Post-breeding population dynamics indicate upslope molt-migration by Wilson's Warblers. J Field Ornithol 2017.
[39] Faaborg J, Holmes RT, Anders AD, et al. Recent advances in understanding migration systems of New World land birds. Ecol Monogr 2010;80:3-48.

[40] Webster MS, Marra PP, Haig SM, Bensch S, Holmes RT. Links between worlds: unraveling migratory connectivity. Trends Ecol Evol 2002;17:76-83.

[41] Rubenstein DR, Chamberlain CP, Holmes RT, et al. Linking breeding and wintering ranges of a migratory songbird using stable isotopes. Science 2002;295:1062-5.

[42] Hobson KA, Van Wilgenburg SL, Roth AM, et al. Golden-winged Warbler migratory connectivity derived from stable isotopes. Boca Raton, FL: CRC Press; 2016. 